\title{
NF-kB signaling pathways regulated by CARMA family of scaffold proteins
}

\author{
Marzenna Blonska ${ }^{1}$, Xin $\operatorname{Lin}^{1}$ \\ ${ }^{I}$ Department of Molecular and Cellular Oncology, University of Texas, M.D. Anderson Cancer Center, 1515 Holcombe Blvd, Unit \\ 108, Houston, TX77030
}

The NF-кB family of transcription factors plays a crucial role in cell activation, survival and proliferation. Its aberrant activity results in cancer, immunodeficiency or autoimmune disorders. Over the past two decades, tremendous progress has been made in our understanding of the signals that regulate NF- $\kappa$ B activation, especially how scaffold

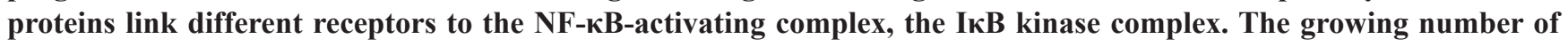
these scaffolds underscores the complexity of the signaling networks in different cell types. In this review, we discuss the role of scaffold molecules in signaling cascades induced by stimulation of antigen receptors, G-protein-coupled receptors and C-type Lectin receptors, resulting in NF- $\mathrm{kB}$ activation. Especially, we focus on the family of Caspase recruitment domain (CARD)-containing proteins known as CARMA and their function in activation of NF- $\kappa B$, as well as the link of these scaffolds to the development of various neoplastic diseases through regulation of NF- $\mathrm{kB}$.

Keywords: CARMA1; CARMA2; CARMA3; CARD9; Bcl10; NF- $\mathrm{kB}$; IKK; NEMO

Cell Research (2011) 21:55-70. doi:10.1038/cr.2010.182; published online 28 December 2010

\section{Introduction}

Scaffold proteins are defined as molecules that bind to at least two other signaling proteins [1]. Scaffold proteins typically do not posses any enzymatic or transcriptional activity, but they have the ability to assemble various combinations of multi-protein complexes, necessary for integration of signals and selective transmission of information from the surface receptors $[1,2]$. In most cases, scaffolds help to localize signaling molecules to specific parts of cell. They also serve as platforms for assembling enzymes and their substrates, restraining the nonspecific access of enzymes to unwanted substrates and protecting from undesirable cellular effects [3]. Some scaffold proteins can have other functions, like coordination of the positive and negative feedback signals or protection of activated proteins from inactivation [1]. Interestingly, scaffold proteins may exhibit distinct functions under different physiological conditions [4]. Also, multiple scaffold/receptor complexes may exist simultaneously,

Correspondence: Xin Lin

Tel: 713-792-8969, Fax: 713-794-3270

E-mail: xllin@mdanderson.org directing both overlapping and distinct cellular events [2].

To date, a large number of scaffolds have been shown to play a crucial role in activation of the nuclear factor $\kappa \mathrm{B}(\mathrm{NF}-\kappa \mathrm{B})$ following stimulation of different receptors [5-9]. NF- $\mathrm{kB}$ is a family of transcription factors that control cell activation, proliferation and survival. Its activity is tightly regulated by interaction with inhibitory proteins, I $\kappa \mathrm{Bs}$, which mask the nuclear localization sequence of NF- $\kappa B$ subunits, thereby sequestering NF- $\kappa$ B in cytoplasm. Upon stimulation, I $\mathrm{I} B$ is phosphorylated by the IKB kinase (IKK) complex, followed with ubiquitinationdependent degradation by the $26 \mathrm{~S}$ proteasome complex. Therefore, NF- $\kappa B$ can be translocated into the nucleus and initiate specific target gene transcription $[5,10]$. In spite of the tremendous progress in the NF- $\mathrm{KB}$ signaling field, the signaling cascades connecting different receptors to the IKK complex remain to be fully determined (Figure 1). Previous studies have revealed the tissue-specific and stimulus-specific roles of many scaffold proteins in regulating NF- $\mathrm{kB}$ signaling networks $[7,8,11,12]$. Among these scaffold proteins, a family of Caspase recruitment domain (CARD)-containing scaffold proteins, known as CARD- and membrane-associated guanylate kinase-like domain-containing protein (CARMA), plays critical roles in recruitment and activation of IKK $[12,13]$. In this 


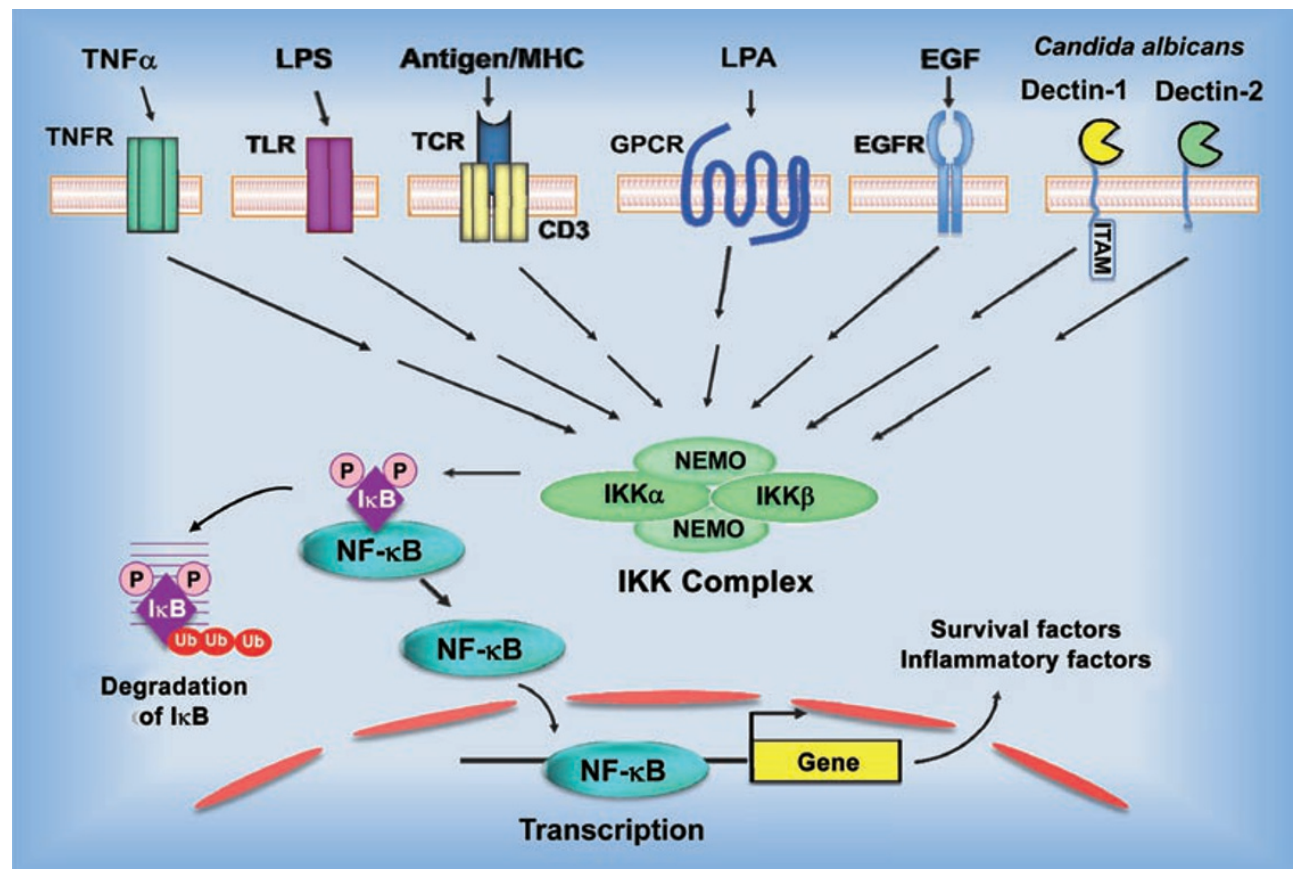

Figure 1 Model of NF-kB activation by the canonical pathway. Stimulation of the surface receptors by different inducers initiates several proximal signaling events resulting in activation of the IKB kinase (IKK) complex, composed of two kinases, IKK $\alpha$ and IKK $\beta$, and the regulatory subunit $\underline{N} F-\kappa B$-essential modulator (NEMO). IKK phosphorylates inhibitor of $\kappa B$ (IKB), which leads to its ubiquitination and subsequent degradation. NF- $\mathrm{KB}$ is then translocated into nuclei and initiates the target gene transcription. TNFR - tumor necrosis factor receptor; TLR - toll like receptor, LPS - lipopolysaccharide; TCR - T-cell receptor; GPCR - G protein-coupled receptors; LPA - Iysophosphatidic acid; EGFR - epidermal growth factor receptor; ITAM - immunoreceptor tyrosine-based activation motif; Ub - ubiquitin.

article, we discuss the role of CARMA family members and other related CARD-containing scaffold proteins in regulation of NF- $\kappa \mathrm{B}$ activation in response to signals induced by the various cell surface receptors.

\section{CARMA family of scaffold proteins}

The CARMA family is conserved among species and has three members, CARMA1, CARMA2, and CARMA3 that are encoded by three different genes [14-16]. They all contain an N-terminal CARD domain, followed with a coiled-coil domain (C-C), a PDZ domain, an SH3 domain, and a Guanylate Kinase-like (GUK) domain in the C-terminus. The structural module of PDZSH3-GUK is also called Membrane-associated GUK (MAGUK) domain. CARMA family members were initially identified based on their CARD domain by bioinformatics approaches and named CARD11 (known as CARMA1 or Bimp3), CARD14 (known as CARMA2 or Bimp2), and CARD10 (known as CARMA3 or Bimp1) $[14,16,17]$. CARMA1, CARMA2, and CARMA3 share high degree of sequence and structural homology (Figure 2), but they exhibit a distinct tissue distribution pattern.
Original studies suggest that CARMA1 is primary expressed in hematopoietic tissues such as spleen, thymus, and peripheral blood leukocyte; CARMA2 is expressed in placenta; and CARMA3 is expressed in a broad range of tissues but not in hematopoietic cells [14-17]. We have analyzed the mRNA microarray data, which were generated from 353 human tissue samples [18] and deposited in the databank (Oncomine 4.4; www.oncomine. org). This analysis revealed that CARMA2 is mainly expressed in mucosa tissues (Figure 3), although the expression pattern of CARMA1 and CARMA3 is consistent with the initial studies [14-17]. This distinct tissue distribution suggests that CARMA family members may have the same function to activate downstream signaling events and play similar roles in different cell types. Indeed, ectopic expression of CARMA family members induces potent activation of NF- $\mathrm{KB}$ in most of cell lines, as well as primary cells $[6,15,19]$. The overexpressed CARMA1 forms a complex with two downstream signaling molecules, Bcl10 (B-cell lymphoma protein 10), another CARD-containing scaffold protein, and MALT1 (Mucosa-associated lymphoid tissue lymphoma translocation protein 1), a caspase-like protein [20]. Previous 
studies demonstrate that signal-dependent formation of the CARMA1-Bcl10-MALT1 complex (commonly known as the CBM complex) recruits downstream signaling components, leading to the activation of NF- $\mathrm{KB}$ [20-22].

\section{CBM proteins in antigen receptor signaling}

By inducing somatic mutations in Jurkat $\mathrm{T}$ cells, our lab obtained a cell line that lacks CARMA1 protein expression. Using this CARMA1-deficient cells, we demonstrated that CARMA1 is required for the T cell receptor (TCR)-induced NF- $\kappa \mathrm{B}$ activity [23]. Independent studies using dominant negative mutants of CARMA1 [24] or small interfering RNA targeting CARMA1 [25] also revealed the crucial role of CARMA1 in NF- $\mathrm{KB}$ activation following TCR ligation. Finally, the genetargeting experiments in mouse have further confirmed that CARMA1 is essential for antigen receptor-induced NF- $\kappa \mathrm{B}$ and JNK activation, but not ERK or p38 activation [26-28]. Although the development and survival of mature $\mathrm{B}$ and $\mathrm{T}$ cells are not significantly affected by CARMA1 deficiency, the signal-induced proliferation of mature cells is severely impaired [26, 27]. Similar defects are observed in Bcl10-deficient lymphocytes [29].

$\mathrm{Bc} 110$ was identified by functional cloning from mucosa-associated lymphoid tissue (MALT) lymphoma cells $[30,31]$ and by bioinformatics approaches as a CARD-containing protein [32-34]. Genetic studies using Bcl10-deficient mice have revealed that Bcl10 is an essential component in the T cell receptor (TCR)- and $B$ cell receptor (BCR)-induced NF- $\kappa B$ activation, and functions downstream of PKC $[29,35]$. Bcl10 contains an N-terminal CARD domain and a C-terminal Ser/Thrrich domain (Figure 2). The CARD domain of Bcl10 is responsible for its association with CARMA1 and TCRinduced oligomerization [36, 37]. Bcl10 oligomers can function as scaffolds for the IKK and Jun N-terminal kinase (JNK) pathways by recruiting and assembling signaling complexes containing kinases and their substrates [12]. In this case, oligomerized Bcl10 associates with JNK2 and its upstream kinases, MKK7 and TAK1, in stimulated Jurkat T cells [38]. The high molecular weight complex of oligomerized Bcl10 was also found to regulate TCR-induced actin polymerization [37]. Interestingly, Bcl10-dependent actin polymerization has a significant impact on phagocytosis in monocytes, but CARMA1 and MALT1 are not involved in this process $[39,40]$.

Similarly to Bcl10, MALT1 (also known as Paracaspase) was first identified by genetic cloning from MALT lymphoma patient samples [41] and bioinformatic approach [42]. Malt1 gene is localized in a break point of chromosome $18 \mathrm{q} 21$ and $\mathrm{t}(11 ; 18)(\mathrm{q} 21 ; \mathrm{q} 21)$ generates API2-MALT1 fusion protein, whereas $\mathrm{t}(14 ; 18)(\mathrm{q} 32 ; \mathrm{q} 21)$ juxtaposes Malt1 gene to the immunoglobulin locus and upregulates its expression [41, 43, 44]. Although transient transfection of wild type MALT1 does not significantly activate NF- $\mathrm{KB}$, overexpression of its oncogenic form potently activates NF- $\mathrm{kB}$ in vitro $[42,45]$. Consistent with these results, transgenic mice expressing E $\mu$-API2-MALT1 have elevated NF- $\kappa B$ activity [46]. On the other hand, genetic inactivation of Malt1 gene in mice impairs TCR-induced NF- $\kappa B$ activation $[47,48]$. However, there are some discrepancies about the role of MALT1 in BCR-induced NF- $\kappa \mathrm{B}$ activation in two mouse models. One study suggests that total NF- $\kappa B$ activity is significantly reduced in MALT1-deficient B cells [47], whereas another gene-targeting study shows that NF- $\kappa B$ activation is almost not affected by MALT1 deficiency upon BCR stimulation [48]. Surprisingly, further work has revealed that the activation of c-Rel isoform of NF$\kappa \mathrm{B}$ is more severely impaired than other isoforms, such as RelA (known as p65) [49]. Thus, it remains to be de-
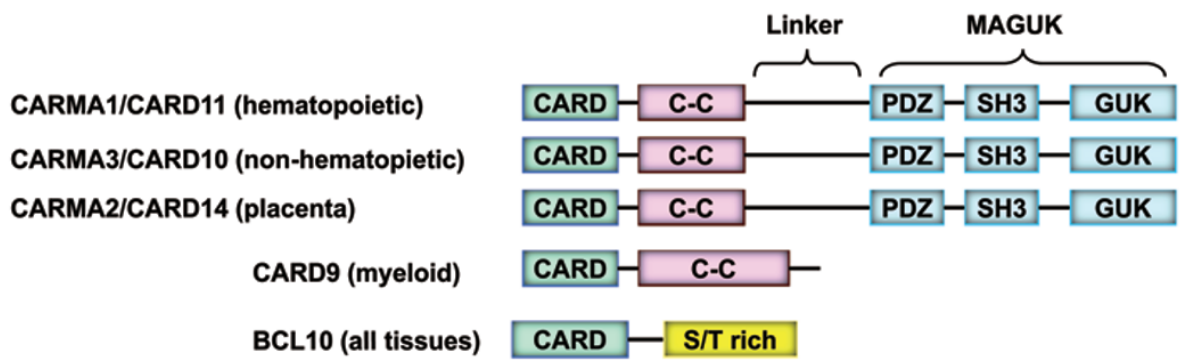

Figure 2 Structures of CARMA1-3, CARD9, Bcl10 and their tissue distribution. CARMA - caspase recruitment domain (CARD)and membrane-asssociated guanylate kinase-like domain-containing protein; Bcl10 - B-cell lymphoma 10; CARD - caspaserecruitment domain; C-C - coiled-coil domain; MAGUK - membrane-associated guanylate kinase (GuK)-like domain; S/T rich - Ser/Thr rich domain. 

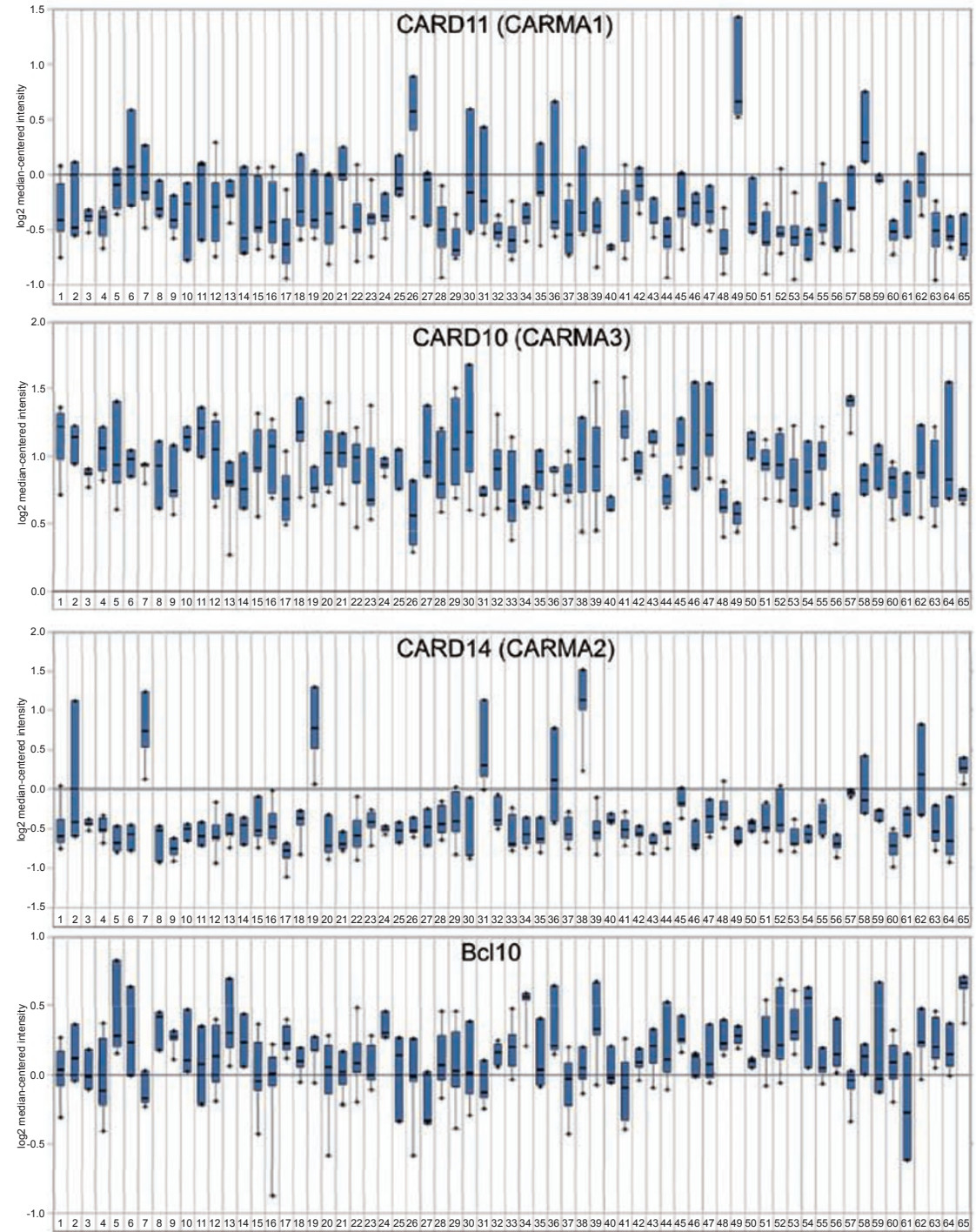

\begin{tabular}{|c|c|c|c|}
\hline egend & & & \\
\hline 1. Accumbens Nucleus & 18. Endometrium & 35. Ovary & 51. Substantia Nigra \\
\hline 2. Adipose Tissue & 19. Esophagus & 36. Papilla of the Tongue & 52. Subthalamic Nucleu \\
\hline 3. Adrenal Cortex & 20. Frontal Lobe & 37. Parietal Lobe & 53. Temporal Lobe \\
\hline 4. Amygdala & 21. Fundus of the Stomach & 38. Pharyngeal Mucosa & 54. Testis \\
\hline 5. Bone Marrow & 22. Hippocampus & 39. Pituitary Gland & 55. Thalamus \\
\hline 6. Bronchus & 23. Hypothalamus & 40. Prostate Gland & 56. Thyroid Gland \\
\hline 7. Buccal Mucosa & 24. Liver & 41. Putamen & 57. Tongue \\
\hline 8. Gastric Cardia & 25. Lung & 42. Pylorus & 58. Tonsil \\
\hline 9. Cardiac Atrium & 26. Lymph Node & 43. Renal Cortex & 59. Trachea \\
\hline 10. Cardiac Ventricle & 27. Mammary Gland & 44. Renal Medulla & 60. Trigeminal Ganglion \\
\hline 11. Cecum & 28. Medulla Oblongata & 45. Salivary Gland & 61. Urethra \\
\hline 12. Cerebellum & 29. Mesencephalon & 46. Saphenous Vein & 62. Vagina \\
\hline 13. Cervix Uteri & 30. Myometrium & 47. Skeletal Muscle Tissue & 63. Ventral Tegmentum \\
\hline 14. Coronary Artery & 31. Nipple & 48. Spinal Cord & 64. Vestibular Nucleus \\
\hline 15. Corpus Callosum & 32. Nodose Ganglion & 49. Spleen & 65. Vulva \\
\hline 16. Cerebral Cortex & 33. Occipital Lobe & 50. Subcutaneous Adipose Tissue & \\
\hline 17. Dorsal Root Ganglion & 34. Omental Adipose $T$ & & \\
\hline
\end{tabular}

Figure 3 Expression patterns of CARMA1, CARMA2, CARMA3 and Bcl10 in 65 different human tissues. Microarray data from the public database were analysed using Oncomine 4.4 tools (www.oncomine.org). Log2 median intensity is shown on Y-axis. 
termined why MALT1 deficiency has more significant impact for the activation of $\mathrm{c}-$ Rel than other isoforms of $\mathrm{NF}-\kappa \mathrm{B}$ in B cells.

The initial characterization of MALT1 did not reveal its protease activity $[42,45]$, and MALT1 has been suggested to serve as an E3 ligase for the regulatory subunit of the IKK complex [50]. Later, it has been shown that MALT1, through its paracaspase domain but in a protease-independent manner, controls caspase- 8 (CASP8) activation, leading to activation of NF-kB and production of IL-2 [51]. However, an independent study indicates that MALT1 has an arginine-directed protease
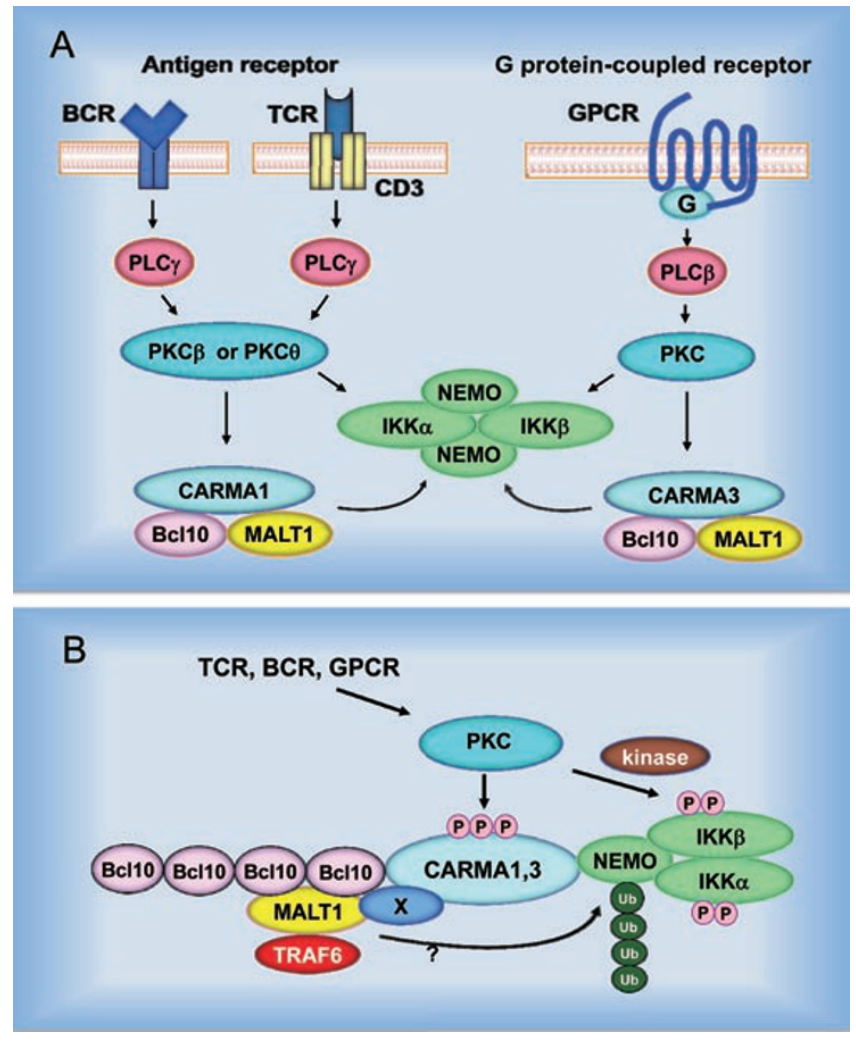

Figure 4 Schematic model of the B-cell receptor (BCR)-, T-cell receptor (TCR) and G protein-coupled receptor-induced NF$\kappa B$ activation. (A) Stimulation of the surface receptor initiates several proximal signaling events that lead to activation of phospholipase $C$ (PLC) and protein kinase $C(P K C)$. The activated PKC phosphorylates CARMA and enables CARMA to associate with the downstream signaling components, Bcl10 and MALT1. Formation of the CBM complex leads to activation of the IKK complex. (B) The CBM complex cooperates with tumor necrosis factor receptor-associated factor 6 (TRAF6) and possibly some unidentified protein $(X)$ to mediate ubiquitination of NEMO. The IKK complex is also phosphorylated in a PKC-dependent manner and both modifications are essential for the IKK kinase activity. activity that is induced following TCR stimulation [52]. The activated MALT1 can process Bcl10 and regulates TCR-induced cell adhesion to fibronectin [52]. This study suggests that MALT1 protease activity is essential for the optimal activation of NF- $\mathrm{KB}$, although it remains to be determined how this activity links to NF- $\mathrm{kB}$. The involvement of MALT1-dependent CASP8 activation in TCR-induced NF- $\mathrm{KB}$ activity is consistent with the previous finding that CASP8 is involved in positive regulation of NF- $\mathrm{KB}$ activity $[53,54]$. In addition, CASP8 and c-FLIP are recruited into lipid rafts following with rapid cleavage of c-FLIP at the CASP8 cleavage site [55]. Together, these studies suggest that an uncharacterized signaling cascade may connect MALT1, CASP8, and c-FLIP to NF- $\kappa B$ activation. Further work is required to address this possible connection.

\section{The CBM complex in natural killer and mast cells}

Besides its critical role in the TCR and BCR signaling, the CBM complex mediates NF- $\mathrm{KB}$ activation induced by the multiple immunoreceptor tyrosine-based activation motif (ITAM)-containing receptors [8, 56, 57]. In natural killer (NK) cells, activation of the ITAM-coupled receptors leads to CARMA1-, Bcl10- and MALT1-dependent induction of NF- $\mathrm{NB}$ and production of proinflammatory cytokines $[56,57]$. However, the CBM complex is dispensable for NK cell-mediated target cell killing [8, 57]. Furthermore, activation of the Fc epsilon receptor I (FceRI) on mast cells also engages Bcl10 and MALT1 to activate NF- $\kappa \mathrm{B}[58,59]$. The Bcl10-Malt1 complex promotes IL- 6 and tumor necrosis factor (TNF)- $\alpha$ release, which are independent of degranulation and leukotriene secretion [58]. However, it remains to be determined whether CARMA1 is also involved in FceR-induced signaling events. Together, these studies indicate that CBM proteins play a critical role in multiple receptor signaling pathways.

\section{The mechanism of $T$ cell receptor-induced CAR- MA1 activation}

Although the molecular mechanism is not fully understand, CARMA1 is recruited into the immunological synapse (also known as lipid raft microdomain) upon TCR stimulation $[24,60,61]$. This recruitment seems to be dependent on at least two steps. First, CARMA1 needs to be localized to the cytoplasmic membrane [24] and the point mutation in the MAGUK domain of CARMA1 (Leu808 replaced with Pro) impairs its membrane localization and recruitment to the immunological synapse [61]. This result is consistent with the function of 
MAGUK domain that is believed to link proteins to the cytoplasmic membrane [62]. The second step for CARMA1 recruitment to the immunological synapse seems to be dependent on its inducible interaction with an adaptor protein known as ADAP (adhesion- and degranulationpromoting adapter protein). Upon TCR engagement, ADAP and CARMA1 are recruited into the immunological synapse, and ADAP deficiency results in impaired CARMA1 translocation leading to reduced NF- $\kappa \mathrm{B}$ activation [63]. However, ADAP is not a membrane protein and it is unlikely that ADAP anchors the MAGUK domain of CARMA1 to the cytoplasmic membrane. Therefore, another unknown protein may be required for anchoring CARMA1 to the cytoplasmic membrane.

Upon TCR ligation, CARMA1 physically associates with protein kinase $\mathrm{C}$ theta $(\mathrm{PKC} \theta)$, and this association is dependent on the linker region (residues 432-671) between the C-C and PDZ domains of CARMA1 (Figure 2) [61]. The linker region is phosphorylated by $\mathrm{PKC} \theta$ (or $\mathrm{PKC} \beta$ in $\mathrm{B}$ cells) in a signal-dependent manner (Figure 4A) $[19,64]$ and two putative PKC phosphorylation sites, Ser552 and Ser645 (in mouse: Ser564 and Ser657), were identified and confirmed in the linker region of human CARMA1 [19, 64, 65]. The inducible phosphorylation of CARMA1 by PKC results in conformational changes that enable CARMA1 to associate with its downstream signaling components $[19,64,66]$.

The linker region of CARMA1 also contains multiple non-PKC sites and other kinases may be involved in its phosphorylation and regulation. Indeed, PDK1, AKT, TAK1, IKK $\beta$, CK1 $\alpha$, and HPK1 have been shown to as- sociate with or may phosphorylate CARMA1 [67-71] Moreover, some kinases may contribute to CARMA1 phosphorylation outside the linker region. Consistent with this notion, calmodulin-dependent protein kinase II (CaMKII) is recruited to the immunological synapse following TCR stimulation, and phosphorylates CARMA1 on Ser109 [72]. Mutation of Ser109 to Ala residue in CARMA1 impairs its biological function [72]. Once activated, CARMA1 recruits the IKK complex $[60,61]$ and other signaling molecules (Table 1) [63, 67-69, 73], including Bcl10 and its pre-associated partner MALT1 [60, 61, 74]. TCR-induced formation of the CARMA1-Bcl10MALT1 complex is critical for IKK activation. It is conceivable that $\mathrm{CBM}$ functions as a molecular platform to assemble IKK with its direct activators [68, 75].

\section{The mechanism of CARMA1-dependent activation of the IKK complex}

$\mathrm{NF}-\kappa \mathrm{B}$ is activated by at least two signaling pathways: the canonical pathway and the non-canonical pathway. These two pathways utilize different IKK complexes to activate downstream signaling. The canonical pathway is activated by the IKK complex containing two catalytic subunits, IKK $\alpha$ and IKK $\beta$, and the regulatory subunit, $\underline{N F-\kappa B-e s s e n t i a l ~ M o d u l a t o r ~(N E M O, ~ a l s o ~ k n o w n ~ a s ~}$ IKK $\gamma$ ) [76-78], which phosphorylates IкBs and induces their degradation. In contrast, the non-canonical pathway is activated by the IKK complex containing IKK $\alpha$ homodimer, which phosphorylates p100 leading to proteolytic processing of p100 into p52 [10]. Our previous

Table 1 CARMA1-interacting proteins

\begin{tabular}{lll}
\hline INTERACTING PROTEIN & BIOLOGICAL FUNCTION & \multicolumn{1}{c}{ REFERENCE } \\
\hline ADAP & adaptor protein, signal transduction & Medeiros, 2007 (63) \\
AKT & kinase & Narayan, 2006 (69) \\
$\beta$-arrestins & adaptor protein, signal transduction & Sun, 2008 (6) \\
Bc110 & scaffold, signal transduction & Bertin, 2001 (14); Gaide, 2001 (15) \\
CaMKII & kinase & Ishiguro, 2006 (72) \\
Cb1-b & E3 ligase & Kojo, 2009 (104) \\
CK1 $\alpha$ & kinase & Bidere, 2009 (70) \\
COP9 $($ CNS5) & adaptor protein, signal transduction & Welteke, 2009 (106) \\
HPK1 & kinase & Brenner, 2009 (71) \\
IKK $\beta$ & kinase & Wegener, 2006 (21); Shinohara, 2007 (65) \\
MALT1 & paracaspase, protease & Che, 2004 (74); Wegener, 2006 (21) \\
NEMO & regulatory protein & Stilo, 2004 (92); Shambharkar, 2007 (79) \\
PDK1 & kinase & Lee, 2005 (67) \\
PKC $\theta$ & kinase & Wang, 2004 (61); Matsumoto, 2005 (19) \\
TAK1 & kinase & Shinohara, 2005 (68) \\
\hline
\end{tabular}


study indicates that CARMA1 is involved in regulating the canonical pathway [79]. Although there is no report implicating a role of CARMA1 or Bcl10 in the noncanonical pathway, one study suggests that MALT1 may be required for BAFF receptor-induced p100 processing [80].

The activation of the IKK complex is dependent on the signal-induced phosphorylation of IKK $\alpha$ and IKK $\beta$ on two Ser residues (Ser176/180 for IKK $\alpha$ and Ser177/181 for IKK $\beta$ ) within the activation loop of the kinase domain $[81,82]$. Although many kinases were shown to phosphorylate IKKs when overexpressed in cells, the genetic evidence indicates that two MAP3K kinases, TAK1 (TGF $\beta$-activated kinase 1) [83-86] and MEKK3 (Mitogen-activated Protein Kinase Kinase Kinase 3) [87, 88], are involved in phosphorylation of these two Ser residues in IKK $\alpha$ and IKK $\beta$. Accumulating evidence indicates that TAK1 [83-86] and MEKK3 [8891] are involved in TNFR-, IL-1 $\beta$ R-, TLR-, and TCRinduced IKK phosphorylation and activation. However, CARMA1 does not control this signal-induced phosphorylation of IKK, instead, CARMA1 directly associates with NEMO [92], and modulates the polyubiquitination of NEMO upon TCR stimulation (Figure 4B) [79].

Although NEMO has no catalytic activity, it is required for the kinase activity of the IKK complex in the canonical NF- $\mathrm{KB}$ pathway. It has been shown that NEMO can specifically recognize Lysine 63 (K63)-linked polyubiquitin chains [93-95], and becomes polyubiquitinated upon activation of NF- $\mathrm{KB}$ signaling cascades [50, 96]. These two properties of NEMO seem to be required for activation of the IKK complex. It is also possible that K63-linked NEMO polyubiquitination allows NEMO oligomerization through cross-recognition by its own ubiquitin-binding domain and leads to generation of the high molecular weight IKK complex [97]. Interestingly, several studies suggest that K63-linked polyubiquitination of NF- $\mathrm{KB}$ signaling components, such as RIP1 [93, 98], IRAK [99], Bcl10 [95], and MALT1 [100], might be recognized by NEMO following stimulation of different receptors. Indeed, it has been shown that TCR ligation leads to K63-linked polyubiquitination of Bcl10 at Lys31 and Lys63 in the CARD domain, and this polyubiquitin chain can be recognized by NEMO [95]. Thus, polyubiquitinated Bcl10 may be involved in a signal-dependent IKK redistribution and possibly activation $[36,95]$. Also, all these results suggest that NEMO might be responsible for the recruitment of the IKK complex to the specific subcellular location and/or to the specific signaling complex. However, how NEMO is involved in activation of the IKK complex still remains to be determined.

The CBM complex most likely serves as a molecular platform to recruit signaling components responsible for the K63-linked polyubiquitination of NEMO [50]. Interestingly, although IKK $\beta$ phosphorylation is not defective in stimulated CARMA1- or Bcl10-deficient cells, the kinase activity of IKK is completely abolished [79], suggesting that the phosphorylation of IKK is not sufficient to induce its kinase activity. Indeed, activation of the IKK complex is not only dependent on IKK phosphorylation but also on CARMA1-dependent NEMO modification [79]. Initially, the physical interaction of NEMO with CARMA family members, was identified by the yeast two-hybrid screening and confirmed by coprecipitation experiments in mammalian cells [92]. Our later study has revealed that NEMO is polyubiquitinated in a CARMA1-dependent manner upon TCR engagement [79], although the mechanism by which CARMA1 regulates NEMO polyubiquitination is not fully defined. One study suggests that the CBM complex recruits TRAF6, and TRAF6 induces K63-linked polyubiquitination of NEMO upon TCR stimulation [75]. Alternatively, MALT1 may induce NEMO ubiquitination at the Lys399 (Lys392 in mice) residue, because NEMO variant with K399R mutation has been shown to interfere with NF-kB activation [50]. However, mice expressing the NEMOK392R mutant are not defective in antigen receptorinduced responses [101]. Therefore, it remains to be determined whether MALT1-dependent polyubiquitination of NEMO is functionally important for TCR-induced responses. In addition, although TRAF6 has been suggested to mediate TCR-induced polyubiquitination of the IKK complex [75], T cell-specific deletion of TRAF6 does not impair TCR-induced NF-KB activation [102], suggesting that either there is a redundant mechanism for TRAF6-mediated activation of IKK or TRAF6 is not involved in the activation of IKK (Figure 4B). Because CARMA1-dependent NEMO polyubiquitination is required for IKK activation, revealing the mechanism by which CARMA1 regulates NEMO polyubiquitination should provide further insight about the regulation of the IKK complex.

\section{Negative regulation of CARMA1 and Bcl10 proteins}

Posttranslational modifications contribute to the regulation of the expression level of CARMA1. Recent studies indicate that phosphorylation of some residues in CARMA1 may suppress CARMA1 function [70, 103]. The Ser637 residue seems to be phosphorylated by PKC isoforms other than $\mathrm{PKC} \theta$ or $\mathrm{PKC} \beta$, and mutation of Ser637 to Ala enhances CARMA1-induced NF- $\kappa B$ activation [103], suggesting that Ser637 phosphorylation negatively regulates CARMA1 function. Another study 
demonstrates that CARMA1 phosphorylation by casein kinase $1 \alpha(\mathrm{CK} 1 \alpha)$ leads to the attenuation of CBM-mediated NF- $\kappa B$ activity [70]. The Ser608 residue within the CARMA1 linker region has been identified as a CK1 $\alpha$ phosphorylation site [70], however, the mechanism by which Ser608 phosphorylation suppresses CARMA1 activity remains unclear.

Recent studies indicate that ubiquitination may also regulate the function of CBM proteins. Formation of the CBM complex appears to be negatively regulated by the E3 ligase Cbl-b [73]. It has been shown that Cbl-b mediates monoubiquitination of CARMA1, which disrupts the CARMA1-Bcl10 interaction without affecting CARMA1 protein stability [104]. On the other hand, K48-linked polyubiquitination leads to the proteasome-mediated degradation of CARMA1 [105]. The C-terminal MAGUK region of CARMA1 seems to be involved in this regulation, since SH3 and GUK domains contain the ubiquitin acceptor sites. In vitro experiments demonstrate that the cellular inhibitor of apoptosis (cIAP) might be an E3 ligase for CARMA1 [105]. Finally, one study shows that CARMA1 interacts with members of the COP9 signalosome, CNS2 and CNS5 [106]. This work suggests that COP9 regulates IKK activity by maintaining stability of the CBM complex and protecting Bcl10 from degradation [106].

Posttranslational modifications also regulate the level of Bcl10. Although the function of the C-terminal Ser/ $\mathrm{Thr}$ rich domain of Bcl10 is not fully determined, several studies suggest that signal-dependent phosphorylation of these Ser and Thr residues may mediate degradation of Bcl10 [21, 107-109], thereby terminating NF- $\kappa B$ activation [109]. Indeed, Bcl10-deficient $T$ cells reconstituted with the Bc110-S138A mutant have prolonged NF- $\kappa B$ activation and enhanced IL-2 production [108]. However, the mechanism by which Bcl10 stability is regulated remains to be defined.

\section{The role of CBM proteins in lymphoma}

Previous studies suggest that CBM proteins are involved in lymphoma pathogenesis [30, 31, 41, 110]. Chromosomal translocations, which lead to the overexpression of Bcl10 and MALT1 or generation of API2MALT1 fusion protein, were found in MALT lymphoma $[30,41,43]$, and the activation of NF- $\mathrm{kB}$ by these oncogenic proteins is believed to be one of the hallmarks of MALT lymphoma. Consistent with this concept, transgenic mice expressing $\mathrm{E} \mu-\mathrm{Bcl10}$ have splenic B-cell expansion and develop marginal zone B-cell lymphoma [111].

Although the CARMA1 gene is not commonly rear- ranged in B- or T-cell lymphomas, elevated CARMA1 expression was found in adult $\mathrm{T}$ cell leukemia [112], primary gastric B cell lymphoma [113] and diffuse large B cell lymphoma (DLBCL) [110]. Importantly, CARMA1 overexpression leads to its oligomerization through the $\mathrm{C}-\mathrm{C}$ domain and activation of the downstream signaling cascades [114]. Recently, pathogenic oligomerization of CARMA1 with subsequent activation of the CBM complex has been found in the activated B-cell (ABC) subtype of DLBCL [115]. This pathogenic CARMA1 oligomerization results from mutations within exons encoding the C-C domain [115]. Screening of patient samples performed independently by three groups has revealed that CARMA1 is mutated in about $10 \%$ of systemic $\mathrm{ABC}-\mathrm{DLBCL}$ and $16 \%$ of primary central nervous system DLBCL [115-117]. The oncogenic mutant of CARMA1 constitutively recruits downstream signaling components [118], and likely induces proteolytic activity of MALT1 $[119,120]$, leading to activation of NF- $\mathrm{KB}$ [115].

Previous studies have shown that NF- $\kappa \mathrm{B}$ activity is critical for the survival of malignant cells in ABC-DLBCL [121], and IKK inhibitors [122] or CARMA1 shRNA [110] are toxic for these cells. Therefore, CARMA1 is considered to be an attractive target for the development of specific anti-lymphoma drugs. Although the detailed mechanism of oncogenic function of CARMA1 remains to be fully elucidated, several lines of evidence are consistent with the hypothesis that mutations and/or overexpression of CARMA1 contribute to the lymphoma cell survival. Further studies are needed to determine whether mutation of CARMA1 alone is sufficient to initiate lymphoma and contributes to the malignant phenotype, such as dissemination, of lymphoma.

\section{CARMA3-mediated NF-кB signaling pathways}

CARMA3 is expressed widely in non-hematopoietic cells and has recently been described as a link between G protein-coupled receptors (GPCRs) and NF- $\mathrm{BB}$ [123]. GPCR is the largest class of transmembrane receptors in the human genome involved in regulation of proliferation, differentiation, and immune response through the wide variety of its ligands [124]. One of them is lysophosphatidic acid (LPA), a bioactive phospholipid that is a component of normal plasma and biological fluids, such as saliva and bronchoalveolar fluid $[125,126]$. LPA is capable of inducing diverse cellular responses by inducing activity of several transcription factors, including $\mathrm{NF}-\kappa \mathrm{B}$ and AP-1 [127].

Genetic deletion of CARMA3 results in diminished LPA-induced NF- $\kappa$ B activation and subsequent IL-8 
production in mouse embryonic fibroblasts (MEF) [123]. Similar defect is observed following stimulation with other GPCR ligands, such as endothelin-1 and angiotensin-II, in the absence of CARMA3 [123, 128, 129]. Importantly, CARMA3 is specifically required for GPCR-induced IKK activity because CARMA3 deficiency does not affect IKK activation by other stimuli such as $\mathrm{TNF} \alpha$ and lipopolysaccharide (LPS) [123].

Recent study also demonstrates that inhibition of CARMA3 in airway epithelial cells reduces LPAmediated NF- $\mathrm{KB}$ activity and the production of NF- $\mathrm{\kappa B}-$ dependent cytokines, TSLP and CCL20 [130]. Both cytokines are produced by airway epithelial cells and play important role in initiating allergic inflammation [131, 132]. Furthermore, forced expression of a dominant-negative CARMA3 mutant (CARD truncation) or treatment of cells with siRNA specifically targeting CARMA3 abrogates LPA-induced signaling in ovarian cancer cells [133].

Similarly to CARMA3, Bcl10- and MALT1-deficient cells have defective NF- $\kappa$ B activation following LPA treatment $[134,135]$. These results indicate that the CARMA3-Bcl10-MALT1 complex may play an analogues role in non-hematopoietic cells as the CARMA1Bcl10-MALT1 complex in the TCR and BCR pathways in hematopoietic cells (Figure 4A). Consistent with this possibility, GPCR-induced ubiquitination of NEMO and activation of the IKK complex is completely defective in the absence of CARMA3 but IKK phosphorylation is intact in these cells [123]. Thus, similarly to CARMA1, CARMA3 mediates the signal-induced polyubiquitination of NEMO (Figure 4B). Interestingly, TRAF6 deficiency also abrogates GPCR-induced NF- $\mathrm{kB}$ activation [123]. Therefore, TRAF6 might function as an E3 ligase to induce K63-linked poly-ubiquitination of NEMO leading to activation of the IKK complex. However, further experimental evidence is needed to prove this hypothesis.

GPCR-mediated signaling leads to phosphorylation and activation of different $\mathrm{PKC}$ isoforms and pretreatment with PKC inhibitors suppresses GPCR-induced $\mathrm{NF}-\kappa \mathrm{B}$ activation $[6,123]$. To date, it is not clear whether any specific PKC isoform is responsible for phosphorylation of CARMA3. It has been reported that PKC $\delta$ mediates NF- $\kappa \mathrm{B}$ activation and IL-8 secretion in response to LPA stimulation in bronchial epithelial cells [136]. Moreover, LPA activates PKC $\alpha$ and induces RAS-PKC $\alpha$ interaction, causing NF- $\kappa B$ activation via the CARMA3BCL10-MALT1 signaling complex in ovarian cancer cells [133]. Therefore, an outstanding question is whether any isoform of PKCs directly phosphorylates CARMA3 and, if it does, which residue of CARMA3 is phosphorylated by PKC. Interestingly, our previous study demonstrates that ectopic expression of CARMA3 in CARMA1-deficient T cells restores TCR-induced NF$\kappa \mathrm{B}$ activation [19], and mutation of Ser520 in CARMA3 (an analogue to Ser552 in CARMA1) to the Ala residue diminished CARMA3's ability to rescue CARMA1 deficiency in T cells [19]. Although Ser520 might be an important phosphorylation site, it is possible that multiple residues in CARMA3 are phosphorylated by PKC, and other kinases may also contribute to CARMA3 activation in the GPCR pathways.

Our previous study has investigated how CARMA3 is linked to the upstream signaling components in the GPCR-induced cascades and found that CARMA3 interacts with $\beta$-arrestin-2 [6]. Upon stimulation, GPCR recruits and associates with the multifunctional scaffold molecules, $\beta$-arrestins [2]. These proteins were initially considered as components to desensitize GPCR activation but more recent studies indicate that $\beta$-arrestins mediate the signal transduction to NF- $\mathrm{kB}$ [137]. Although there are four members of the arrestin family in the human genome, only $\beta$-arrestin 1 and $\beta$-arrestin 2 are ubiquitously expressed in most tissues and function downstream of GPCRs [137]. The study from our laboratory demonstrates that $\beta$-arrestin 2 , but not $\beta$-arrestin 1 , is required for LPA-induced NF- $\kappa$ B activation and subsequent IL-6 expression [6]. Mechanistically, $\beta$-arrestin 2 associates with CARMA3 and most likely recruits CARMA3 into the receptor complex. Similar to CARMA3-deficient cells, GPCR-induced IKK kinase activity is completely defective in $\beta$-arrestin $2 \mathrm{KO}$ mouse embryonic fibroblasts [6].

\section{CBM proteins in the receptor tyrosine kinase path- ways}

Several growth factors, including Epidermal Growth Factor (EGF) [138-140], Insulin-like Growth Factor (IGF) [141-143], Platelet-Derived Growth Factor (PDGF) $[144,145]$, and Fibroblast Growth Factor (bFGF) [146, 147], can also induce weak, but notable NF- $\mathrm{kB}$ activation through their receptors that belong to a family of receptor tyrosine kinases (RTKs). Although the signaling pathways induced by this family of receptors have been intensively studied, the mechanism by which RTKs activate NF- $\mathrm{KB}$ is not fully defined, and the functional significance of RTK-induced NF- $\kappa \mathrm{B}$ activation in cell proliferation and survival has not been fully appreciated. Our recent studies indicate that CARMA3 and Bcl10 are required for EGFR-induced NF- $\mathrm{\kappa B}$ activation and cancer progression (Jiang and Lin, unpublished data). Therefore, further studies are required to determine how CARMA3 and $\mathrm{Bcl} 10$ are involved in the signaling pathways in- 
duced by EGFR or other RTKs.

\section{CARD9-mediated NF-кB signaling pathways}

CARD9 is another CARD-containing protein and has some similarity to CARMA family members. It was identified through a database search for CARD-containing proteins and shown to interact with Bcl10 [148]. Its expression seems to be restricted to myeloid cells, mainly macrophages, dendritic cells and neutrophils [148-150]. Although CARD9 is structurally related to the CARMA family, it lacks the C-terminal MAGUK domain (Figure 2) that determinates plasma membrane localization. Therefore, CARD9 may localize in cytosol and be recruited to the receptor complex. Recently, three groups independently generated CARD9-deficient mice and revealed its essential role in the control of innate immunity $[7,149$, $150]$.

Initial characterization of CARD9-deficient mice indicates that CARD9 is required for anti-fungal immune responses [149]. This study shows that CARD9 is required for NF- $\mathrm{\kappa B}$ activation induced by zymosan, a $\beta$-glucan component from yeast cell wall [149]. Because zymosan can activate the signaling pathways induced by Dectin-1, a C-type lectin receptor, it has been proposed that CARD9 mediates Dectin-1-induced NF- $\mathrm{BB}$ activation [149]. However, recent studies from our laboratory have surprisingly found that zymosan can still effectively activate NF- $\mathrm{NB}$ in macrophages from an independently generated CARD9-deficient mouse strain [151], suggesting that Dectin-1-induced NF- $\kappa$ B activation may also be induced through a CARD9-independent pathway [151]. Therefore, the requirement of CARD9 in Dectin-1-induced NF- $\mathrm{BB}$ activation needs to be further investigated. Besides the Dectin-1 pathway, it has been demonstrated that CARD9 also mediates the signaling induced by other C-type lectin receptors such as Dectin-2 [151, 152] and Mincle [153]. These receptors have been implicated to act as the pattern recognition receptors for fungi $[154$, $155]$.

It has been suggested that CARD9 functions downstream of the tyrosine kinase Syk and couples Bcl10/ MALT1 to activate classical NF- $\kappa B$ [7, 151, 152, 156, 157]. Similarly to CARMA1 and CARMA3, CARD9 is required for activation of the IKK complex [151]. Consistent with this model, CARD9-deficient macrophages and dendritic cells have impaired expression of TNF- $\alpha$, IL-6, and IL-12 in response to the stimulation with fungal particles [149, 151, 152, 157] and CARD9-deficient mice are more susceptible to infection with the fungus Candida albicans [149, 151, 152, 156, 158].

Published studies suggest that Dectin-1 preferentially

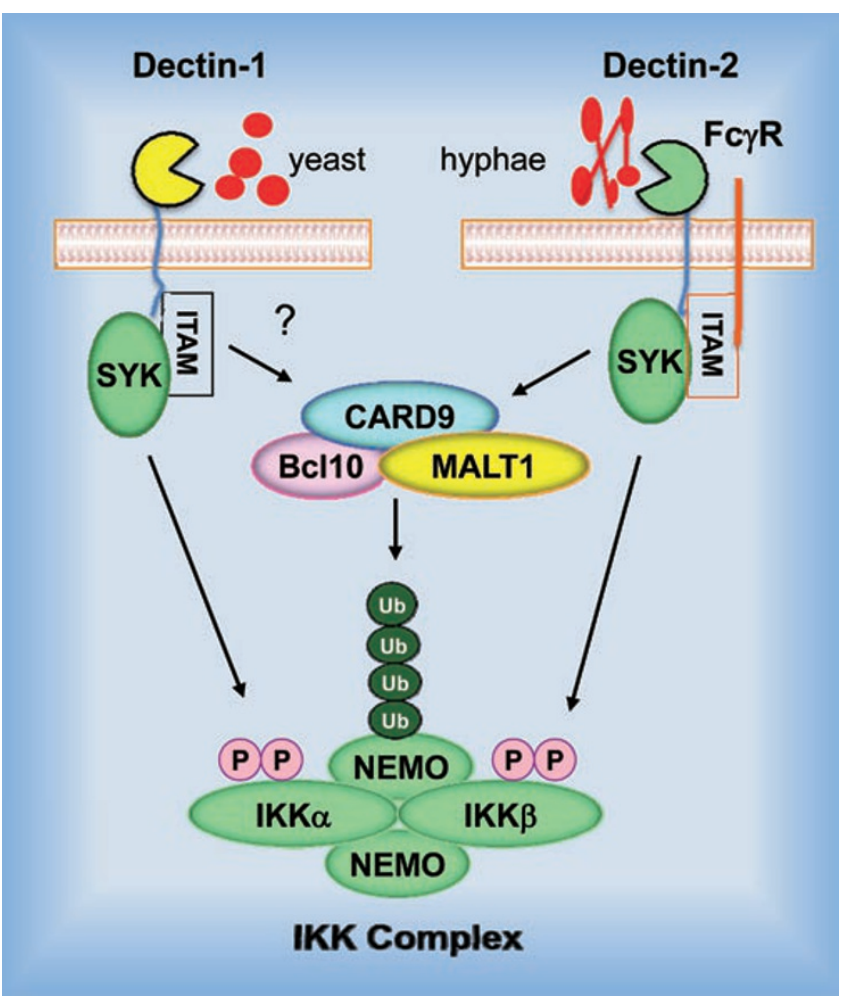

Figure 5 CARD9 in the C-type lectin receptor signaling. Activation of the Dectin-1 receptor by the yeast-like, unicellular form of $C$. albicans or the Dectin-2 receptor by the hyphal form of $C$. albicans leads to a sequential activation of tyrosine kinase Syk, the CARD9-Bcl10-MALT1 complex and IKK. In this signaling cascade Syk mediates IKK phosphorylation, whereas CARD9 controls NEMO polyubiquitination.

binds the yeast-like, unicellular form of C. albicans, whereas the Dectin-2 signaling is induced by the hyphal form $[152,158]$. The proximal signaling cascade leads to a sequential activation of Syk, CARD9, and IKK following stimulation of these C-type lectin receptors (Figure 5) [13]. However, the latest work argues that although Syk is required for both Dectin-1- and Dectin-2-induced $\mathrm{NF}-\kappa \mathrm{B}$ activation, CARD9 is only required for Dectin2 -induced NF- $\kappa B$ activation [151]. In addition, Syk and CARD9 do not seem to function in a linear cascade as Syk mediates IKK phosphorylation, whereas CARD9 controls NEMO polyubiquitination [151].

Recent studies also suggest that CARD9 mediates the $\mathrm{NF}-\kappa \mathrm{B}$ activation induced by several ITAM-associated receptors, including those associating with $\mathrm{FcR} \gamma$ and DAP12 in myeloid cells [7]. Interestingly, it has been proposed that the CARD9-containing complex mediates NF- $\mathrm{KB}$ activation induced by the ITAM-associated receptors in myeloid cells, whereas the CARMA1-containing complex mediates NF- $\mathrm{kB}$ activation induced by ITAM- 
associated receptors in lymphoid lineage cells [8]. However, it remains to be determined why ITAM-associated receptors in myeloid cells utilize the CARD9-dependent, but not CARMA1-dependent, pathway to activate NF$\kappa \mathrm{B}$, given that CARMA1 is also expressed in myeloid cells.

\section{Other functions of CARD9}

Several studies also demonstrate that CARD9 is involved in immunity to intracellular bacteria Listeria monocytogenes [7, 150, 159] and Mycobacteruim tuberculosis [160]. The latest work suggests that CARD9 controls the production of reactive oxygen species (ROS) by regulating the LyGDI-Rac1 complex following the phagocytosis of microorganisms by macrophages [159]. CARD9 is also found to be involved in anti-viral responses [150, 161]. The CARD9-Bcl10 module appears to be an essential component of the RNA helicase RIG-I-dependent proinflammatory response to certain RNA viruses that leads to IL-1 $\beta$ production [161].

Another study links CARD9 to kidney cancer [162]. It has been shown that tumor suppressor VHL associates with CARD9 and promotes inhibitory phosphorylation of CARD9 by casein kinase 2 (CK2). Inactivation of the $V H L$ gene is often observed in renal cell carcinoma and may lead to increased NF- $\mathrm{kB}$ activity. Ectopic expression of CARD9 mutants that can not be phosphorylated leads to increased NF- $\mathrm{BB}$ activity and decreased apoptosis in VHL-defective renal carcinoma cells, whereas knockdown of CARD9 suppresses NF$\kappa \mathrm{B}$ activity in these cells [162]. Although the role of CARD9 phosphorylation by CK2 is not clear, the authors speculate that this modification may promote an inhibitory intra- or inter-molecular interaction or prevent the binding of CARD9 to NEMO or other proteins required for its activity [162]. One discrepancy of this regulatory mechanism of posttranslational CARD9 modification with previous results is that CARD9 is mainly expressed in myeloid cells and the expression level of CARD9 in renal cells is very low. Nevertheless, future studies are needed to investigate the role of CARD9 in non-myeloid cells.

\section{Concluding remarks}

Significant progress towards understanding the function of the CARMA family of scaffold proteins in the $\mathrm{NF}-\mathrm{\kappa B}$ signaling pathway has been made during the past several years. However, more research is clearly required to define the CARMA-mediated signaling and the role of these proteins in disease, especially in cancer. Still, the open question is the precise molecular mechanism by which CBM activates the IKK complex. Although CARMA/CARD9-dependent NEMO polyubiquitination seems to be important for IKK activity, it is still possible that CBM mediates some additional modifications of the IKK complex members. Moreover, although previous studies indicate that CARMA2 is exclusively expressed in placenta and mucosal cells, the role of CARMA2 is completely unknown. Therefore, further studies are needed to reveal the role of CARMA2 in these tissues.

\section{Acknowledgments}

This work was supported by grants from the National Institutes of Health (RO1GM065899, RO1GM079451, RO1AI050848) to XL. MB is a Special Fellow of The Leukemia and Lymphoma Society.

\section{References}

1 Shaw AS, Filbert EL. Scaffold proteins and immune-cell signalling. Nat Rev Immunol 2009; 9:47-56.

2 Defea KA. Beta-arrestins as regulators of signal termination and transduction: How do they determine what to scaffold? Cell Signal 2010 Oct 12. doi:10.1016/j.cellsig.2010.10.004

3 Burack WR, Cheng AM, Shaw AS. Scaffolds, adaptors and linkers of TCR signaling: theory and practice. Curr Opin Immunol 2002; 14:312-316.

4 Locasale JW, Shaw AS, Chakraborty AK. Scaffold proteins confer diverse regulatory properties to protein kinase cascades. Proc Natl Acad Sci USA 2007; 104:13307-13312.

5 Hayden MS, Ghosh S. Shared principles in NF-kappaB signaling. Cell 2008; 132:344-362.

6 Sun J, Lin X. Beta-arrestin 2 is required for lysophosphatidic acid-induced NF-kappaB activation. Proc Natl Acad Sci USA 2008; 105:17085-17090.

7 Hara H, Ishihara C, Takeuchi A, et al. The adaptor protein CARD9 is essential for the activation of myeloid cells through ITAM-associated and Toll-like receptors. Nat Immunol 2007; 8:619-629.

8 Hara H, Ishihara C, Takeuchi A, et al. Cell type-specific regulation of ITAM-mediated NF-kappaB activation by the adaptors, CARMA1 and CARD9. J Immunol 2008; 181:918930.

9 Sun SC, Ley SC. New insights into NF-kappaB regulation and function. Trends Immunol 2008; 29:469-478.

10 Hacker H, Karin M. Regulation and function of IKK and IKK-related kinases. Sci STKE 2006; 2006:re13.

11 Simeoni L, Kliche S, Lindquist J, Schraven B. Adaptors and linkers in T and B cells. Curr Opin Immunol 2004; 16:304313.

12 Blonska M, Lin X. CARMA1-mediated NF-kappaB and JNK activation in lymphocytes. Immunol Rev 2009; 228:199-211.

13 Hara H, Saito T. CARD9 versus CARMA1 in innate and adaptive immunity. Trends Immunol 2009; 30:234-242.

14 Bertin J, Wang L, Guo Y, et al. CARD11 and CARD14 are novel caspase recruitment domain (CARD)/membraneassociated guanylate kinase (MAGUK) family members that interact with BCL10 and activate NF-kappa B. J Biol Chem 
2001; 276:11877-11882.

15 Gaide O, Martinon F, Micheau O, et al. Carma1, a CARDcontaining binding partner of Bcl10, induces Bcl10 phosphorylation and NF-kappaB activation. FEBS Lett 2001; 496:121-127.

16 Wang L, Guo Y, Huang WJ, et al. Card10 is a novel caspase recruitment domain/membrane-associated guanylate kinase family member that interacts with BCL10 and activates NFkappa B. J Biol Chem 2001; 276:21405-21409.

17 McAllister-Lucas LM, Inohara N, Lucas PC, et al. Bimp1, a MAGUK family member linking protein kinase $\mathrm{C}$ activation to Bcl10-mediated NF-kappaB induction. J Biol Chem 2001; 276:30589-30597.

18 Roth RB, Hevezi P, Lee J, et al. Gene expression analyses reveal molecular relationships among 20 regions of the human CNS. Neurogenetics 2006; 7:67-80.

19 Matsumoto R, Wang D, Blonska M et al. Phosphorylation of CARMA1 plays a critical role in T Cell receptor-mediated NF-kappaB activation. Immunity 2005; 23:575-585.

20 Lin X, Wang D. The roles of CARMA1, Bcl10, and MALT1 in antigen receptor signaling. Semin Immunol 2004; 16:429435 .

21 Wegener E, Oeckinghaus A, Papadopoulou N, et al. Essential role for IkappaB kinase beta in remodeling Carma1-Bcl10Malt1 complexes upon T cell activation. Mol Cell 2006; 23:13-23.

22 Wegener E, Krappmann D. CARD-Bcl10-Malt1 signalosomes: missing link to NF-kappaB. Sci STKE 2007; 2007:pe21.

23 Wang D, You Y, Case SM, et al. A requirement for CARMA1 in TCR-induced NF-kappa B activation. Nat Immunol 2002; 3:830-835.

24 Gaide O, Favier B, Legler DF, et al. CARMA1 is a critical lipid raft-associated regulator of TCR-induced NF-kappa B activation. Nat Immunol 2002; 3:836-843.

25 Pomerantz JL, Denny EM, Baltimore D. CARD11 mediates factor-specific activation of NF-kappaB by the T cell receptor complex. EMBO J 2002; 21:5184-5194.

26 Hara $\mathrm{H}$, Wada $\mathrm{T}$, Bakal $\mathrm{C}$, et al. The MAGUK family protein CARD11 is essential for lymphocyte activation. Immunity 2003; 18:763-775.

27 Egawa T, Albrecht B, Favier B, et al. Requirement for CARMA1 in antigen receptor-induced NF-kappa B activation and lymphocyte proliferation. Curr Biol 2003; 13:1252-1258.

28 Newton K, Dixit V. Mice lacking the CARD of CARMA1 exhibit defective B lymphocyte development and impaired proliferation of their B and T lymphocytes. Curr Biol 2003; 13:1247-1251.

29 Ruland J, Duncan GS, Elia A, et al. Bcl10 is a positive regulator of antigen receptor-induced activation of NFkappaB and neural tube closure. Cell 2001; 104:33-42.

30 Willis TG, Jadayel DM, Du MQ, et al. Bcl10 is involved in $\mathrm{t}(1 ; 14)(\mathrm{p} 22 ; \mathrm{q} 32)$ of MALT B cell lymphoma and mutated in multiple tumor types. Cell 1999; 96:35-45.

31 Zhang Q, Siebert R, Yan M, et al. Inactivating mutations and overexpression of BCL10, a caspase recruitment domaincontaining gene, in MALT lymphoma with $\mathrm{t}(1 ; 14)(\mathrm{p} 22 ; \mathrm{q} 32)$. Nat Genet 1999; 22:63-68.

32 Yan M, Lee J, Schilbach S, Goddard A, Dixit V. mE10, a novel caspase recruitment domain-containing proapoptotic molecule. J Biol Chem 1999; 274:10287-10292.

33 Thome M, Martinon F, Hofmann K et al. Equine herpesvirus-2 E10 gene product, but not its cellular homologue, activates NF-kappaB transcription factor and c-Jun N-terminal kinase. J Biol Chem 1999; 274:9962-9968.

34 Koseki T, Inohara N, Chen S et al. CIPER, a novel NF kappaB-activating protein containing a caspase recruitment domain with homology to Herpesvirus-2 protein E10. J Biol Chem 1999; 274:9955-9961.

35 Xue L, Morris SW, Orihuela C, et al. Defective development and function of Bcl10-deficient follicular, marginal zone and B1 B cells. Nat Immunol 2003; 4:857-865.

36 Schaefer BC, Kappler JW, Kupfer A, Marrack P. Complex and dynamic redistribution of NF-kappaB signaling intermediates in response to $\mathrm{T}$ cell receptor stimulation. Proc Natl Acad Sci USA 2004; 101:1004-1009.

37 Rossman JS, Stoicheva NG, Langel FD et al. POLKADOTS are foci of functional interactions in T-Cell receptor-mediated signaling to NF-kappaB. Mol Biol Cell 2006; 17:2166-2176.

38 Blonska M, Pappu BP, Matsumoto R, et al. The CARMA1Bcl10 signaling complex selectively regulates JNK2 kinase in the T cell receptor-signaling pathway. Immunity 2007; 26:5566.

39 Rueda D, Gaide O, Ho L, et al. Bcl10 controls TCR- and FcgammaR-induced actin polymerization. J Immunol 2007; 178:4373-4384.

40 Thome M, Charton JE, Pelzer C, Hailfinger S. Antigen receptor signaling to NF-kappaB via CARMA1, BCL10, and MALT1. Cold Spring Harb Perspect Biol 2010; 2:a003004.

41 Akagi T, Motegi M, Tamura A, et al. A novel gene, MALT1 at $18 \mathrm{q} 21$, is involved in $\mathrm{t}(11 ; 18)(\mathrm{q} 21 ; \mathrm{q} 21)$ found in low-grade B-cell lymphoma of mucosa-associated lymphoid tissue. Oncogene 1999; 18:5785-5794.

42 Uren AG, O'Rourke K, Aravind LA, et al. Identification of paracaspases and metacaspases: two ancient families of caspase-like proteins, one of which plays a key role in MALT lymphoma. Mol Cell 2000; 6:961-967.

43 Ye H, Gong L, Liu H, et al. MALT lymphoma with $\mathrm{t}(14 ; 18)(\mathrm{q} 32 ; \mathrm{q} 21) / \mathrm{IGH}-\mathrm{MALT} 1$ is characterized by strong cytoplasmic MALT1 and BCL10 expression. J Pathol 2005; 205:293-301.

44 Du MQ. MALT lymphoma : recent advances in aetiology and molecular genetics. J Clin Exp Hematop 2007; 47:31-42.

45 Lucas PC, Yonezumi M, Inohara N, et al. Bcl10 and MALT1, independent targets of chromosomal translocation in malt lymphoma, cooperate in a novel NF-kappa B signaling pathway. J Biol Chem 2001; 276:19012-19019.

46 Baens M, Fevery S, Sagaert X, et al. Selective expansion of marginal zone B cells in Emicro-API2-MALT1 mice is linked to enhanced IkappaB kinase gamma polyubiquitination. Cancer Res 2006; 66:5270-5277.

47 Ruefli-Brasse AA, French DM, Dixit VM. Regulation of NFkappaB-dependent lymphocyte activation and development by paracaspase. Science 2003; 302:1581-1584.

48 Ruland J, Duncan GS, Wakeham A, Mak TW. Differential requirement for Malt1 in $\mathrm{T}$ and $\mathrm{B}$ cell antigen receptor signaling. Immunity 2003; 19:749-758.

49 Ferch U, zum Buschenfelde CM, Gewies A, et al. MALT1 di- 
rects B cell receptor-induced canonical nuclear factor-kappaB signaling selectively to the c-Rel subunit. Nat Immunol 2007; 8:984-991.

50 Zhou H, Wertz I, O'Rourke K, et al. Bcl10 activates the NFkappaB pathway through ubiquitination of NEMO. Nature 2004; 427:167-171.

51 Kawadler H, Gantz MA, Riley JL, Yang X. The paracaspase MALT1 controls caspase- 8 activation during lymphocyte proliferation. Mol Cell 2008; 31:415-421.

52 Rebeaud F, Hailfinger S, Posevitz-Fejfar A, et al. The proteolytic activity of the paracaspase MALT1 is key in T cell activation. Nat Immunol 2008; 9:272-281.

$53 \mathrm{Su} \mathrm{H}$, Bidere N, Zheng L, et al. Requirement for caspase-8 in NF-kappaB activation by antigen receptor. Science 2005; 307:1465-1468.

54 Bidere N, Snow AL, Sakai K, Zheng L, Lenardo MJ. Caspase- 8 regulation by direct interaction with TRAF6 in T cell receptor-induced NF-kappaB activation. Curr Biol 2006; 16:1666-1671.

55 Misra RS, Russell JQ, Koenig A, et al. Caspase-8 and c-FLIPL associate in lipid rafts with NF-kappaB adaptors during T cell activation. $J$ Biol Chem 2007; 282:1936519374.

56 Malarkannan S, Regunathan J, Chu H, et al. Bcl10 plays a divergent role in NK cell-mediated cytotoxicity and cytokine generation. J Immunol 2007; 179:3752-3762.

57 Gross O, Grupp C, Steinberg C, et al. Multiple ITAM-coupled NK-cell receptors engage the Bcl10/Malt1 complex via Carma1 for NF-kappaB and MAPK activation to selectively control cytokine production. Blood 2008; 112:2421-2428.

58 Klemm S, Gutermuth J, Hultner L, et al. The Bcl10-Malt1 complex segregates Fc epsilon RI-mediated nuclear factor kappa B activation and cytokine production from mast cell degranulation. J Exp Med 2006; 203:337-347.

59 Chen Y, Pappu BP, Zeng H, et al. B cell lymphoma 10 is essential for FcepsilonR-mediated degranulation and IL-6 production in mast cells. J Immunol 2007; 178:49-57.

60 Hara H, Bakal C, Wada T, et al. The molecular adapter Carmal controls entry of IkappaB kinase into the central immune synapse. J Exp Med 2004; 200:1167-1177.

61 Wang D, Matsumoto R, You Y, et al. CD3/CD28 costimulation-induced NF-kappaB activation is mediated by recruitment of protein kinase $\mathrm{C}$-theta, $\mathrm{Bcl10}$, and IkappaB kinase beta to the immunological synapse through CARMA1. Mol Cell Biol 2004; 24:164-171.

62 Dimitratos SD, Woods DF, Stathakis DG, Bryant PJ. Signaling pathways are focused at specialized regions of the plasma membrane by scaffolding proteins of the MAGUK family. Bioessays 1999; 21:912-921.

63 Medeiros RB, Burbach BJ, Mueller KL, et al. Regulation of NF-kappaB activation in T cells via association of the adapter proteins ADAP and CARMA1. Science 2007; 316:754-758.

64 Sommer K, Guo B, Pomerantz JL, et al. Phosphorylation of the CARMA1 linker controls NF-kappaB activation. Immunity 2005; 23:561-574.

65 Shinohara H, Maeda S, Watarai H, Kurosaki T. IkappaB kinase beta-induced phosphorylation of CARMA1 contributes to CARMA1 Bcl10 MALT1 complex formation in B cells. $J$ Exp Med 2007; 204:3285-3293.
66 McCully RR, Pomerantz JL. The protein kinase C-responsive inhibitory domain of CARD11 functions in NF-kappaB activation to regulate the association of multiple signaling cofactors that differentially depend on Bcl10 and MALT1 for association. Mol Cell Biol 2008; 28:5668-5686.

67 Lee KY, D'Acquisto F, Hayden MS, Shim JH, Ghosh S. PDK1 nucleates $T$ cell receptor-induced signaling complex for NF-kappaB activation. Science 2005; 308:114-118.

68 Shinohara H, Yasuda T, Aiba Y, et al. PKC beta regulates BCR-mediated IKK activation by facilitating the interaction between TAK1 and CARMA1. J Exp Med 2005; 202:14231431.

69 Narayan P, Holt B, Tosti R, Kane LP. CARMA1 is required for Akt-mediated NF-kappaB activation in T cells. Mol Cell Biol 2006; 26:2327-2336.

70 Bidere N, Ngo VN, Lee J, et al. Casein kinase 1alpha governs antigen-receptor-induced NF-kappaB activation and human lymphoma cell survival. Nature 2009; 458:92-96.

71 Brenner D, Brechmann M, Rohling S, et al. Phosphorylation of CARMA1 by HPK1 is critical for NF-kappaB activation in T cells. Proc Natl Acad Sci USA 2009; 106:14508-14513.

72 Ishiguro K, Green T, Rapley J, et al. Ca2+/calmodulindependent protein kinase II is a modulator of CARMA1mediated NF-kappaB activation. Mol Cell Biol 2006; 26:5497-5508.

73 Qiao G, Li Z, Molinero L, et al. T-cell receptor-induced NFkappaB activation is negatively regulated by E3 ubiquitin ligase Cbl-b. Mol Cell Biol 2008; 28:2470-2480.

74 Che T, You Y, Wang D, et al. MALT1/paracaspase is a signaling component downstream of CARMA1 and mediates T cell receptor-induced NF-kappaB activation. J Biol Chem 2004; 279:15870-15876.

75 Sun L, Deng L, Ea CK, Xia ZP, Chen ZJ. The TRAF6 ubiquitin ligase and TAK1 kinase mediate IKK activation by BCL10 and MALT1 in T lymphocytes. Mol Cell 2004; 14:289-301.

76 Zandi E, Rothwarf DM, Delhase M, Hayakawa M, Karin M. The IkappaB kinase complex (IKK) contains two kinase subunits, IKKalpha and IKKbeta, necessary for IkappaB phosphorylation and NF-kappaB activation. Cell 1997; 91:243-252.

77 Rothwarf DM, Zandi E, Natoli G, Karin M. IKK-gamma is an essential regulatory subunit of the IkappaB kinase complex. Nature 1998; 395:297-300.

$78 \mathrm{Li} \mathrm{ZW,} \mathrm{Chu} \mathrm{W,} \mathrm{Hu} \mathrm{Y,} \mathrm{et} \mathrm{al.} \mathrm{The} \mathrm{IKKbeta} \mathrm{subunit} \mathrm{of} \mathrm{IkappaB}$ kinase (IKK) is essential for nuclear factor kappaB activation and prevention of apoptosis. J Exp Med 1999; 189:18391845.

79 Shambharkar PB, Blonska M, Pappu B P, et al. Phosphorylation and ubiquitination of the IkappaB kinase complex by two distinct signaling pathways. EMBO J 2007; 26:1794-1805.

80 Tusche MW, Ward LA, Vu F, et al. Differential requirement of MALT1 for BAFF-induced outcomes in B cell subsets. $J$ Exp Med 2009; 206:2671-2683.

81 Delhase M, Hayakawa M, Chen Y, Karin M. Positive and negative regulation of IkappaB kinase activity through IKKbeta subunit phosphorylation. Science 1999; 284:309-313.

82 Ling L, Cao Z, Goeddel DV. NF-kappaB-inducing kinase ac- 
tivates IKK-alpha by phosphorylation of Ser-176. Proc Natl Acad Sci USA 1998; 95:3792-3797.

83 Sato S, Sanjo H, Tsujimura T, et al. TAK1 is indispensable for development of $\mathrm{T}$ cells and prevention of colitis by the generation of regulatory T cells. Int Immunol 2006; 18:14051411.

84 Shim JH, Xiao C, Paschal AE, et al. TAK1, but not TAB1 or TAB2, plays an essential role in multiple signaling pathways in vivo. Genes Dev 2005; 19:2668-2681.

85 Wan YY, Chi H, Xie M, Schneider MD, Flavell RA. The kinase TAK1 integrates antigen and cytokine receptor signaling for T cell development, survival and function. Nat Immunol 2006; 7:851-858.

86 Liu HH, Xie M, Schneider MD, Chen ZJ. Essential role of TAK1 in thymocyte development and activation. Proc Natl Acad Sci USA 2006; 103:11677-11682.

87 Sun W, Li H, Yu Y, et al. MEKK3 is required for lysophosphatidic acid-induced NF-kappaB activation. Cell Signal 2009; 21:1488-1494.

88 Shinohara H, Yamasaki S, Maeda S, Saito T, Kurosaki T. Regulation of NF-kappaB-dependent T cell activation and development by MEKK3. Int Immunol 2009; 21:393-401.

89 Yang J, Lin Y, Guo Z, et al. The essential role of MEKK3 in TNF-induced NF-kappaB activation. Nat Immunol 2001; 2:620-624.

90 Huang Q, Yang J, Lin Y, et al. Differential regulation of interleukin 1 receptor and Toll-like receptor signaling by MEKK3. Nat Immunol 2004; 5:98-103.

91 Abbasi S, Su B, Kellems RE, Yang J, Xia Y. The essential role of MEKK3 signaling in angiotensin II-induced calcineurin/nuclear factor of activated T-cells activation. $J$ Biol Chem 2005; 280:36737-36746.

92 Stilo R, Liguoro D, Di Jeso B, et al. Physical and functional interaction of CARMA1 and CARMA3 with Ikappa kinase gamma-NFkappaB essential modulator. J Biol Chem 2004; 279:34323-34331.

93 Ea CK, Deng L, Xia ZP, Pineda G, Chen ZJ. Activation of IKK by TNFalpha requires site-specific ubiquitination of RIP1 and polyubiquitin binding by NEMO. Mol Cell 2006; 22:245-257.

94 Wu CJ, Conze DB, Li T, Srinivasula SM, Ashwell JD. Sensing of Lys 63-linked polyubiquitination by NEMO is a key event in NF-kappaB activation. Nat Cell Biol 2006; 8:398-406.

$95 \mathrm{Wu} \mathrm{CJ}$, Ashwell JD. NEMO recognition of ubiquitinated Bcl10 is required for T cell receptor-mediated NF-kappaB activation. Proc Natl Acad Sci USA 2008; 105:3023-3028.

96 Tang ED, Wang CY, Xiong Y, Guan KL. A role for NFkappaB essential modifier/IkappaB kinase-gamma (NEMO/ IKKgamma) ubiquitination in the activation of the IkappaB kinase complex by tumor necrosis factor-alpha. $\mathrm{J} \mathrm{Biol} \mathrm{Chem}$ 2003; 278:37297-37305.

97 Israel A. The IKK complex, a central regulator of NF-kappaB activation. Cold Spring Harb Perspect Biol 2010; 2:a000158.

98 Li H, Kobayashi M, Blonska M, You Y, Lin X. Ubiquitination of RIP is required for tumor necrosis factor alpha-induced NF-kappaB activation. $J$ Biol Chem 2006; 281:13636-13643.

99 Conze DB, Wu CJ, Thomas JA, Landstrom A, Ashwell JD. Lys63-linked polyubiquitination of IRAK-1 is required for interleukin-1 receptor- and toll-like receptor-mediated NF-
kappaB activation. Mol Cell Biol 2008; 28:3538-3547.

100 Oeckinghaus A, Wegener E, Welteke V, et al. Malt 1 ubiquitination triggers NF-kappaB signaling upon T-cell activation. EMBO J 2007; 26:4634-4645.

101 Ni CY, Wu ZH, Florence WC, et al. Cutting edge: K63-linked polyubiquitination of NEMO modulates TLR signaling and inflammation in vivo. J Immunol 2008; 180:7107-7111.

102 King CG, Kobayashi T, Cejas PJ, et al. TRAF6 is a T cellintrinsic negative regulator required for the maintenance of immune homeostasis. Nat Med 2006; 12:1088-1092.

103 Moreno-Garcia ME, Sommer K, Haftmann C, et al. Serine 649 phosphorylation within the protein kinase C-regulated domain down-regulates CARMA1 activity in lymphocytes. $J$ Immunol 2009; 183:7362-7370.

104 Kojo S, Elly C, Harada Y, et al. Mechanisms of NKT cell anergy induction involve Cbl-b-promoted monoubiquitination of CARMA1. Proc Natl Acad Sci USA 2009; 106:1784717851.

105 Moreno-Garcia ME, Sommer K, Shinohara H, et al. MAGUK-controlled ubiquitination of CARMA1 modulates lymphocyte NF-kappaB activity. Mol Cell Biol 2010; 30:922934.

106 Welteke V, Eitelhuber A, Duwel M, et al. COP9 signalosome controls the Carma1-Bc110-Malt1 complex upon T-cell stimulation. EMBO Rep 2009; 10:642-648.

107 Ishiguro K, Ando T, Goto H, Xavier R. Bcl10 is phosphorylated on Ser138 by $\mathrm{Ca} 2+/$ calmodulin-dependent protein kinase II. Mol Immunol 2007; 44:2095-2100.

108 Zeng H, Di L, Fu G, et al. Phosphorylation of Bcl10 negatively regulates T-cell receptor-mediated NF-kappaB activation. Mol Cell Biol 2007; 27:5235-5245.

109 Lobry C, Lopez T, Israel A, Weil R. Negative feedback loop in $\mathrm{T}$ cell activation through IkappaB kinase-induced phosphorylation and degradation of Bcl10. Proc Natl Acad Sci USA 2007; 104:908-913.

110 Ngo VN, Davis RE, Lamy L, et al. A loss-of-function RNA interference screen for molecular targets in cancer. Nature 2006; 441:106-110.

111 Li Z, Wang H, Xue L, et al. Emu-BCL10 mice exhibit constitutive activation of both canonical and noncanonical NF-kappaB pathways generating marginal zone (MZ) B-cell expansion as a precursor to splenic MZ lymphoma. Blood 2009; 114:4158-4168.

112 Oshiro A, Tagawa H, Ohshima K, et al. Identification of subtype-specific genomic alterations in aggressive adult T-cell leukemia/lymphoma. Blood 2006; 107:4500-4507.

113 Nakamura S, Matsumoto T, Yada S, et al. Overexpression of caspase recruitment domain (CARD) membrane-associated guanylate kinase 1 (CARMA1) and CARD9 in primary gastric B-cell lymphoma. Cancer 2005; 104:1885-1893.

114 Tanner MJ, Hanel W, Gaffen SL, Lin X. CARMA1 coiledcoil domain is involved in the oligomerization and subcellular localization of CARMA1 and is required for T cell receptorinduced NF-kappaB activation. J Biol Chem 2007; 282:17141-17147.

115 Lenz G, Davis RE, Ngo VN, et al. Oncogenic CARD11 mutations in human diffuse large B cell lymphoma. Science 2008; 319:1676-1679.

116 Compagno M, Lim WK, Grunn A, et al. Mutations of 
multiple genes cause deregulation of NF-kappaB in diffuse large B-cell lymphoma. Nature 2009; 459:717-721.

117 Montesinos-Rongen M, Schmitz R, Brunn A, et al. Mutations of CARD11 but not TNFAIP3 may activate the NF-kappaB pathway in primary CNS lymphoma. Acta Neuropathol 2010; 120:529-535.

118 Lamason RL, McCully RR, Lew SM, Pomerantz JL. Oncogenic CARD11 Mutations Induce Hyperactive Signaling by Disrupting Autoinhibition by the PKC-Responsive Inhibitory Domain. Biochemistry 2010; 49:8240-8250.

119 Hailfinger S, Lenz G, Ngo V, et al. Essential role of MALT1 protease activity in activated B cell-like diffuse large B-cell lymphoma. Proc Natl Acad Sci USA 2009; 106:19946-19951.

120 Ferch U, Kloo B, Gewies A, et al. Inhibition of MALT1 protease activity is selectively toxic for activated B celllike diffuse large B cell lymphoma cells. J Exp Med 2009; 206:2313-2320.

121 Davis RE, Brown KD, Siebenlist U, Staudt LM. Constitutive nuclear factor kappaB activity is required for survival of activated B cell-like diffuse large B cell lymphoma cells. $J$ Exp Med 2001; 194:1861-1874.

122 Lam LT, Davis RE, Pierce J, et al. Small molecule inhibitors of IkappaB kinase are selectively toxic for subgroups of diffuse large B-cell lymphoma defined by gene expression profiling. Clin Cancer Res 2005; 11:28-40.

123 Grabiner BC, Blonska M, Lin PC, et al. CARMA3 deficiency abrogates $G$ protein-coupled receptor-induced NF-\{kappa\}B activation. Genes Dev 2007; 21:984-996.

124 Lefkowitz RJ. Historical review: a brief history and personal retrospective of seven-transmembrane receptors. Trends Pharmacol Sci 2004; 25:413-422.

125 Mills GB, Moolenaar WH. The emerging role of lysophosphatidic acid in cancer. Nat Rev Cancer 2003; 3:582-591.

126 Zhao Y, Tong J, He D, et al. Role of lysophosphatidic acid receptor LPA2 in the development of allergic airway inflammation in a murine model of asthma. Respir Res 2009; 10:114.

127 Ye RD. Regulation of nuclear factor kappaB activation by G-protein-coupled receptors. J Leukoc Biol 2001; 70:839848.

128 McAllister-Lucas LM, Ruland J, Siu K, et al. CARMA3/ Bc110/MALT1-dependent NF-kappaB activation mediates angiotensin II-responsive inflammatory signaling in nonimmune cells. Proc Natl Acad Sci USA 2007; 104:139144.

129 McAllister-Lucas LM, Jin X, Gu S, et al. The CARMA3Bc110-MALT1 signalosome promotes angiotensin IIdependent vascular inflammation and atherogenesis. $J$ Biol Chem 2010; 285:25880-25884.

130 Medoff BD, Landry AL, Wittbold KA, et al. CARMA3 mediates lysophosphatidic acid-stimulated cytokine secretion by bronchial epithelial cells. Am J Respir Cell Mol Biol 2009; 40:286-294.

131 Zhao Y, Natarajan V. Lysophosphatidic acid signaling in airway epithelium: role in airway inflammation and remodeling. Cell Signal 2009; 21:367-377.

132 Georas SN, Berdyshev E, Hubbard W, et al. Lysophosphatidic acid is detectable in human bronchoalveolar lavage fluids at baseline and increased after segmental allergen challenge.
Clin Exp Allergy 2007; 37:311-322.

133 Mahanivong C, Chen HM, Yee SW, et al. Protein kinase C alpha-CARMA3 signaling axis links Ras to NF-kappa B for lysophosphatidic acid-induced urokinase plasminogen activator expression in ovarian cancer cells. Oncogene 2008; 27:1273-1280.

134 Klemm S, Zimmermann S, Peschel C, Mak TW, Ruland J. Bcl10 and Malt1 control lysophosphatidic acid-induced NFkappaB activation and cytokine production. Proc Natl Acad Sci USA 2007; 104:134-138.

135 Wang D, You Y, Lin PC, et al. Bcl10 plays a critical role in NF-kappaB activation induced by $\mathrm{G}$ protein-coupled receptors. Proc Natl Acad Sci USA 2007; 104:145-150.

136 Cummings R, Zhao Y, Jacoby D, et al. Protein kinase Cdelta mediates lysophosphatidic acid-induced NF-kappaB activation and interleukin- 8 secretion in human bronchial epithelial cells. J Biol Chem 2004; 279:41085-41094.

137 Lefkowitz RJ, Shenoy SK. Transduction of receptor signals by beta-arrestins. Science 2005; 308:512-517.

138 Sun L, Carpenter G. Epidermal growth factor activation of NF-kappaB is mediated through IkappaBalpha degradation and intracellular free calcium. Oncogene 1998; 16:20952102.

139 Biswas DK, Cruz AP, Gansberger E, Pardee AB. Epidermal growth factor-induced nuclear factor kappa B activation: A major pathway of cell-cycle progression in estrogen-receptor negative breast cancer cells. Proc Natl Acad Sci USA 2000; 97:8542-8547.

140 Biswas DK, Iglehart JD. Linkage between EGFR family receptors and nuclear factor kappaB (NF-kappaB) signaling in breast cancer. J Cell Physiol 2006; 209:645-652.

141 Kim HJ, Litzenburger BC, Cui X, et al. Constitutively active type I insulin-like growth factor receptor causes transformation and xenograft growth of immortalized mammary epithelial cells and is accompanied by an epithelial-to-mesenchymal transition mediated by NF-kappaB and snail. Mol Cell Biol 2007; 27:3165-3175.

142 Pons S, Torres-Aleman I. Insulin-like growth factor-I stimulates dephosphorylation of ikappa B through the serine phosphatase calcineurin (protein phosphatase 2B). J Biol Chem 2000; 275:38620-38625.

143 Kaliman P, Canicio J, Testar X, Palacin M, Zorzano A. Insulin-like growth factor-II, phosphatidylinositol 3-kinase, nuclear factor-kappaB and inducible nitric-oxide synthase define a common myogenic signaling pathway. $J$ Biol Chem 1999; 274:17437-17444.

144 Olashaw NE, Kowalik TF, Huang ES, Pledger WJ. Induction of NF-kappa B-like activity by platelet-derived growth factor in mouse fibroblasts. Mol Biol Cell 1992; 3:1131-1139.

145 Romashkova JA, Makarov SS. NF-kappaB is a target of AKT in anti-apoptotic PDGF signalling. Nature 1999; 401:86-90.

146 Byrd VM, Ballard DW, Miller GG, Thomas JW. Fibroblast growth factor-1 (FGF-1) enhances IL-2 production and nuclear translocation of NF-kappaB in FGF receptor-bearing Jurkat T cells. J Immunol 1999; 162:5853-5859.

147 Bushdid PB, Chen CL, Brantley DM, et al. NF-kappaB mediates FGF signal regulation of msx-1 expression. Dev Biol 2001; 237:107-115.

148 Bertin J, Guo Y, Wang L, et al. CARD9 is a novel caspase 
recruitment domain-containing protein that interacts with BCL10/CLAP and activates NF-kappa B. J Biol Chem 2000; 275:41082-41086.

149 Gross O, Gewies A, Finger K, et al. Card9 controls a nonTLR signalling pathway for innate anti-fungal immunity. Nature 2006; 442:651-656.

150 Hsu YM, Zhang Y, You Y, et al. The adaptor protein CARD9 is required for innate immune responses to intracellular pathogens. Nat Immunol 2007; 8:198-205.

151 Bi L, Gojestani S, Wu W, et al. CARD9 mediates dectin2-induced IkappaBalpha kinase ubiquitination leading to activation of NF-kappaB in response to stimulation by the hyphal form of Candida albicans. J Biol Chem 2010; 285:25969-25977.

152 Robinson MJ, Osorio F, Rosas M, et al. Dectin-2 is a Sykcoupled pattern recognition receptor crucial for Th17 responses to fungal infection. J Exp Med 2009; 206:2037-2051.

153 Yamasaki S, Ishikawa E, Sakuma M, et al. Mincle is an ITAM-coupled activating receptor that senses damaged cells. Nat Immunol 2008; 9:1179-1188.

154 Willment JA, Brown GD. C-type lectin receptors in antifungal immunity. Trends Microbiol 2008; 16:27-32.

155 Graham LM, Brown GD. The Dectin-2 family of C-type lectins in immunity and homeostasis. Cytokine 2009; 48:148155.

156 LeibundGut-Landmann S, Gross O, Robinson MJ, et al. Syk- and CARD9-dependent coupling of innate immunity to the induction of T helper cells that produce interleukin 17. Nat Immunol 2007; 8:630-638.

157 Goodridge HS, Shimada T, Wolf AJ, et al. Differential use of CARD9 by dectin-1 in macrophages and dendritic cells. $J$ Immunol 2009; 182:1146-1154.

158 Saijo S, Ikeda S, Yamabe K, et al. Dectin-2 recognition of alpha-mannans and induction of Th17 cell differentiation is essential for host defense against Candida albicans. Immunity 2010; 32:681-691.

$159 \mathrm{Wu}$ W, Hsu YM, Bi L, Songyang Z, Lin X. CARD9 facilitates microbe-elicited production of reactive oxygen species by regulating the LyGDI-Rac1 complex. Nat Immunol 2009; 10:1208-1214.

160 Werninghaus K, Babiak A, Gross O, et al. Adjuvanticity of a synthetic cord factor analogue for subunit Mycobacterium tuberculosis vaccination requires FcRgamma-Syk-Card9dependent innate immune activation. J Exp Med 2009; 206:89-97.

161 Poeck H, Bscheider M, Gross O, et al. Recognition of RNA virus by RIG-I results in activation of CARD9 and inflammasome signaling for interleukin 1 beta production. Nat Immunol 2010; 11:63-69.

162 Yang H, Minamishima YA, Yan Q, et al. pVHL acts as an adaptor to promote the inhibitory phosphorylation of the NFkappaB agonist Card9 by CK2. Mol Cell 2007; 28:15-27. 